Cahiers $d u$ MONDE RUSSE

\section{Cahiers du monde russe}

Russie - Empire russe - Union soviétique et États indépendants

\title{
Zoja Vasil'evna Dmitrieva, Vytnye i opisnye knigi Kirillo-Belozerskogo monastyrja XVI-XVII VV.
}

\section{André Berelowitch}

\section{OpenEdition \\ Journals}

Édition électronique

URL : https://journals.openedition.org/monderusse/4096

DOI : 10.4000/monderusse.4096

ISSN : $1777-5388$

Éditeur

Éditions de l'EHESS

Édition imprimée

Date de publication : 1 octobre 2003

Pagination : 694-699

ISBN : 2-7132-1833-0

ISSN : $1252-6576$

\section{Référence électronique}

André Berelowitch, «Zoja Vasil'evna Dmitrieva, Vytnye i opisnye knigi Kirillo-Belozerskogo monastyrja xvi-xvII VV. », Cahiers du monde russe [En ligne], 44/4 | 2003, mis en ligne le 19 juin 2009, consulté le 03 septembre 2022. URL : http://journals.openedition.org/monderusse/4096 ; DOI : https://doi.org/ 10.4000/monderusse.4096

Ce document a été généré automatiquement le 3 septembre 2022

Tous droits réservés 


\title{
Zoja Vasil'evna Dmitrieva, Vytnye i opisnye knigi Kirillo-Belozerskogo monastyrja XVI-XVII VV.
}

\author{
André Berelowitch
}

\section{RÉFÉRENCE}

Zoja Vasil'evna DMITRIEVA, Vytnye i opisnye knigi Kirillo-Belozerskogo monastyrja XVI-XVII vv. (Censiers et registres d'inventaires du monastère Saint-Cyrille de Beloozero, $\mathrm{XVI}^{\mathrm{e}}$-XVII ${ }^{\mathrm{e}}$ siècles). Saint-Pétersbourg, « Dmitrij Bulanin », 2003, 346 p.

1 L'ouvrage de Z. V. Dmitrieva joue sur deux registres, et c'est ce qui en fait la complexité. En apparence, il s'agit d'une monographie classique d'étude des sources (istočnikovedenie, Urkundenwissenschaft) qui porte sur les archives domaniales d'un monastère devenu dès la seconde moitié $d u \mathrm{XVI}^{\mathrm{e}}$ siècle l'un des plus grands propriétaires fonciers du pays. En réalité, l'auteur ne se prive pas de tirer ses conclusions des sources qu'elle présente, ce qui lui permet de renouveler, sur un certain nombre de points essentiels, l'histoire agraire de la Russie à une étape cruciale: le siècle qui précède, le siècle qui suit l'asservissement de la paysannerie.

2 Très peu d'archives seigneuriales ont été conservées pour cette période. Celles de SaintCyrille, qui attirent depuis plus d'un siècle l'attention des historiens ${ }^{1}$ et que Z. V. Dmitrieva connaît à la perfection pour y avoir travaillé ces trente dernières années, nous sont parvenues presque intactes : c'est dire leur importance. Il faut en savoir gré au chapitre du monastère et aux cellériers (kelar') successifs, responsables de l'élaboration des documents de comptabilité courante, mais aussi aux autorités civiles et religieuses, qui sont à l'origine des inventaires récapitulatifs de 1559, 1601, et 1668.

3 L'enquête de 1559 est probablement le résultat de la politique de remise en ordre des monastères décidée par le synode « des Cent chapitres » (Stoglav) de 1551. Elle aboutit à la rédaction de trois registres distincts. 
4 Le premier, intitulé semennik ( registre des emblavures »), énumère les tenanciers village par village. Il indique pour chacun la quantité de céréales qu'il a empruntée au monastère pour ensemencer sa tenure, ainsi que l'assiette, ou base de calcul, des redevances qu'il doit acquitter. Cette assiette est estimée en vyt', terme qui correspond assez exactement au "manse " des campagnes françaises ${ }^{2}$. Manse entier, demi-manse, quart de manse sont strictement proportionnels, dans les limites d'un même terroir villageois, à la superficie des terres labourées dont le tenancier dispose ${ }^{3}$. Le second registre est un obročnik (entre " censier » et « cueilloir » $\left.{ }^{4}\right)$ : noms des tenanciers, parts de manse, et montants effectifs des redevances en grains. Le troisième est un denežnyj obročnik, un censier des redevances en argent ou mixtes imposées à ceux des paysans (ils exploitent $30 \%$ des surfaces cultivées) qui sèment leurs propres céréales.

5 C'est l'ensemble de ces documents que l'auteur propose d'appeler du terme générique vytnye knigi (littéralement " registres des manses », donc « censiers ») pour les distinguer d'une autre variété de cadastres, les piscovye knigi, établis à des fins fiscales par les agents de la monarchie.

6 En 1601, Boris Godunov pourrait avoir mis à profit les dissensions au sein du monastère pour faire remettre en culture les labours abandonnés. Les envoyés de Moscou dressent l'inventaire complet des bâtiments et des biens meubles ${ }^{5}$. Ce sont eux encore qui rédigent, la même année, un terrier (perepisnaja kniga votčin) décrivant les patrimoines du monastère ${ }^{6}$. Les redevances sont diminuées, voire supprimées, mais en contrepartie on augmente la corvée de labour sur les terres vacantes. Mesures tout éphémères d'ailleurs, puisqu'elles sont abrogées dès l'année suivante, comme le prouve le nouveau censier dont les moines ont pris l'initiative.

7 L'inventaire de 1668, enfin, qui témoigne des évolutions du XVII siècle, est dressé à l'occasion de la passation des pouvoirs de l'abbé Moïse à son successeur Nicétas. Ce remarquable document statistique donne entre autres une liste nominative des moines (reproduite annexe 7): ils sont 227, assistés par 589 serviteurs et gardés par 22 mousquetaires (Saint-Cyrille est aussi une forteresse et une prison). Les 13798 paysans de sexe mâle vivant sur des tenures hébergent 443 commensaux (podsosedniki) ; avec les 2594 " hôtes " ${ }^{7}$ (bobyli), ils occupent 3913 feux répartis sur 761 bourgs, villages et hameaux.

Ces sources massives et comparables entre elles, moyennant certaines précautions, complétées par d'autres plus ponctuelles, mais tout aussi précieuses, qu'il est impossible d'énumérer ici, sont décrites par Z.V. Dmitrieva avec une minutie exemplaire : analyse codicologique, datation, genèse, filiation des documents - c'est toute la structure des archives monastiques qui est ainsi révélée au lecteur.

9 Elles conduisent l'auteur à des conclusions saisissantes. Je me bornerai à en résumer l'essentiel, renonçant à évoquer les renseignements techniques, métrologiques, bibliographiques de tous ordres qu'il faut glaner au fil des pages, la plume à la main.

Premier sujet de perplexité : les prêts de semence de 1559, consentis apparemment sine die et sans intérêt à 2000 tenanciers, portent sur une quantité totale d'environ 1000 tonnes de céréales, ou 500 kilos par foyer - la consommation annuelle d'un adulte ${ }^{8} . \mathrm{Ni}$ avant, ni après, les archives du monastère n'ont gardé trace d'une opération comparable par son ampleur. Comment l'expliquer? Selon Z.V.Dmitrieva, les avances consenties sont de celles que l'on accordait aux paysans nouvellement installés sur un domaine: l'enregistrement du prêt serait alors l'équivalent du contrat (porjadnaja) par lequel le 
tenancier s'engageait vis-à-vis de son seigneur. De fait, le milieu du $\mathrm{XvI}^{\mathrm{e}}$ siècle est une période d'intense colonisation dans le district de Beloozero (p. 27-28).

11 Le monastère peut se permettre ces largesses : les redevances lui apportent annuellement plus de 500 tonnes de grain, les princes Starickij lui ont fait don de près de 350 tonnes au cours des années précédentes, et ses réserves, en 1601, sont légèrement inférieures à 1400 tonnes. Presque tout est consommé sur place, par les moines, les serviteurs, les desservants des 82 églises du domaine monastique, les mendiants, les voyageurs et les visiteurs de marque, sans compter les avances aux paysans et même à des personnes tout à fait étrangères au couvent (p. 29-30, 211).

Un système de crédit très élaboré préside aux avances de céréales. Dans chaque canton, ou groupe de villages (appelé indifféremment ključ ou volost'), les paysans élisent un grenetier juré (žitnyj celoval'nik), chargé de la gestion du grenier sous le contrôle du grand grenetier (bol'šoj žitnik) du couvent, auquel il doit soumettre ses comptes à sa sortie de mandat ${ }^{9}$. Ces livres de comptes, qui ont survécu, permettent, source incomparable, de reconstituer la vie quotidienne des villages ${ }^{10}$. Il arrive que l'assemblée des villageois dresse elle-même la liste des nécessiteux qui méritent une avance (1671). Lorsque les grains du couvent ne suffisent pas, en 1680 par exemple, les paysans demandent à ce que le «blé des mousquetaires» (streleckij hleb), impôt en nature qui devrait être livré au gouvernement, soit conservé dans le grenier local jusqu'après les semailles (p. 38-39). Au terme d'une démonstration parfois obscure (p.40), Z.V. Dmitrieva conclut que ces avances, qui doivent être remboursées intégralement à la moisson, ne comportent pas d'intérêt.

13 Autre sujet d'étonnement : bien loin d'augmenter, les redevances des paysans, qu'on les calcule par manse ou par unité de surface, ont tendance à stagner, voire à diminuer entre 1559 et les années 1670, cependant que les manses se fragmentent de plus en plus (p. 211-237). Il faut attendre l'extrême fin $\mathrm{du} \mathrm{XVII}^{\mathrm{e}}$ siècle pour que des changements notables interviennent, résultant probablement d'une pression fiscale accrue de l'État: les redevances en grains sont converties en argent (3 roubles par manse) et une véritable avalanche de corvées s'abat sur les tenanciers, désormais asservis, du monastère. Même alors, le chapitre consent, devant leurs protestations, à ramener la redevance à 2,5 roubles et interdit désormais toutes les corvées non prévues par la charte statutaire de 1654 (p. 237-242).

14 Les enquêtes ordonnées, dans un remarquable esprit d'équité, par le cellérier Mathieu Nikiforov ${ }^{11}$ permettent de confronter la superficie des labours soumis à redevances (tjaglaja pašnja) avec celle réellement exploitée par les paysans. Elles sont calculées par l'auteur pour la portion du domaine couverte par les sources (censiers de 1660 et de 1665). Alors que la tenure proprement dite est en moyenne de 2,4 desjatina par feu dans les trois soles, soit 2,6 hectares, l'exploitation effective dépasse 10 desjatina ${ }^{12}$ ! Les trois quarts de cette surface étaient occupés par les labours, un quart par les prés (tableau 9, p. 208). Mais pourquoi ces quelque 9 hectares supplémentaires étaient-ils exemptés de redevances? Peut-être parce qu'ils étaient mis en repos de longue durée (perelog) dans le cadre d'une rotation empirique des cultures, combinant jachère et assolement triennal ou même biennal (p. 205-208).

15 Enfin, après avoir rappelé la longue controverse sur le degré de confiance que l'on doit accorder aux cadastres officiels (p. 243-248), Z. V. Dmitrieva compare les données de ceux-ci, notamment celui de 1618, avec les informations fournies par les censiers et cueilloirs conventuels. Le cadastrage de 1618, sollicité par Saint-Cyrille pour corriger les 
résultats des précédents (1613 et 1615), intervient, il faut le rappeler, à la fin du Temps des troubles. Le nombre de feux, comparé à 1613, a été divisé par 7, la superficie des labours par 22 ! Or le censier révisé de 1618, élaboré par les moines presque en même temps que le cadastre officiel, compte dans le canton de l'okolomonastyr'e 135 maîtres de maison et 150 paysans mâles. Le cadastre n'y a recensé que 5 feux paysans et 3 hôtises! Dans le canton de Knutovo, 58 paysans ont acquitté leur redevance en 1618, le cadastre n'en compte que 5. Les autres sont portés disparus (tués par les Polono-Lituaniens ou les cosaques, morts de faim ou partis à la ville), alors qu'on les retrouve, bien vivants, non seulement dans les archives monastiques, mais aussi dans le cadastre de 1626-1627. De toute évidence, le chapitre, en 1618, a obtenu ce qu'il voulait: une presque totale exemption d'impôt de ses paysans, dans une période, il est vrai, réellement difficile (p. 273-278). Il faut donc se garder de toute conclusion à l'emporte-pièce: chaque cadastre est un cas d'espèce et ne doit être exploité par l'historien que lorsqu'il a soigneusement confronté ses données avec celles des autres sources existantes (p. 284).

Le tableau que l'auteur nous présente est donc très loin des images d'Épinal accréditées naguère par les manuels soviétiques, où l'on voyait des paysans soumis à une exploitation "sans cesse accrue" par des "féodaux ecclésiastiques" sans pitié ni scrupule. Ce renouvellement complet de l'histoire agraire est l'œuvre d'une pléiade d'historiens russes, que l'on ne saurait tous citer ici, et notamment de la prestigieuse équipe de Leningrad, dirigée par Alexandre Šapiro ${ }^{13}$, dont Z. V. Dmitrieva a fait partie.

Aussi complet, aussi sérieux soit-il, son livre n'est évidemment pas sans défaut. Les imperfections de forme sont peu nombreuses : le manuscrit reproduit p. 90 est transcrit, p. 88, en omettant deux mots (« ruki» et «Molčanova»); p. 112, la note 265 devrait renvoyer à l'annexe 3, p. 291, de même que la note 70, p.223, qui oublie de signaler l'annexe 2 ; p. 256-257, on découvre trois villages qui tous portent le numéro trois ; p. 277, le texte indique 18 villages dans le canton de Knutovo et 13 dans celui de Koldoma, alors que la liste, p. 274-277, en compte respectivement 17 et 16 . Il ne s'agit là que de menues négligences.

Plus gênants sont les défauts formels qui nuisent à la compréhension du texte. Dans certains tableaux, les sources sont indiquées uniquement par des cotes d'archives; en l'absence d'une table récapitulative des manuscrits utilisés, le lecteur ne peut pas toujours retrouver la nature ou la date de la source. Surtout, le mode d'exposition par moments confus et embarrassé de l'auteur, mais parfois aussi sa confiance excessive dans des techniques éprouvées, l'empêchent de poser les problèmes ou de développer son argumentation avec toute la clarté et la logique désirables. Je n'en retiendrai que deux exemples.

19 Lorsqu'il s'agit de savoir si les prêts de céréales sont consentis sans intérêt aux paysans, Z.V. Dmitrieva convertit les redevances en grain en leur équivalent monétaire en utilisant les données de A. G. Man'kov ${ }^{14}$ comme si ce procédé allait de soi (p. 26). Or, il n'existe pas de véritable série de prix en Russie avant le XvIII ${ }^{\mathrm{e}}$ siècle et on peut mettre en doute la légitimité de la méthode lorsqu'il s'agit, comme c'est le cas, d'une économie d'auto-consommation, fonctionnant en circuit presque fermé. Elle fait valoir par ailleurs que les avances de grain consenties au printemps sont restituées à l'identique en automne. Mais elle n'explore pas la possibilité d'une inclusion de l'intérêt dans le montant du prêt, ruse classique visant à tourner la prohibition de l'usure (p. 39-40).

Quand elle aborde le problème, embrouillé s'il en est, du partage périodique des terres (p. 208-210), Z. V. Dmitrieva opère à juste titre une distinction entre l'égalisation des 
tenures, qui n'est contestée par personne, et celle des exploitations, c'est-à-dire le peredel, ou partage des terres proprement dit, bien attesté aux XVIII ${ }^{e}$ et $\mathrm{XIX}^{\mathrm{e}}$ siècles au sein des communautés paysannes. N.P. Pavlov-Sil'vanskij et A. I. Kopanev ${ }^{15}$ (ce dernier n'est d'ailleurs pas cité) nient énergiquement son existence au XVII siècle. Elle est affirmée en revanche par L.S. Prokof'eva, N.A. Gorskaja et dans une certaine mesure par Z.V. Dmitrieva, qui s'appuie sur une pétition de 1679. Il est vrai que les textes cités par les trois historiennes semblent leur donner raison, mais ils sont en même temps très ambigus et, faute d'avoir tracé une ligne de démarcation suffisamment claire entre égalisation des tenures et partage des terres, les arguments de Z.V. Dmitrieva n'emportent pas vraiment l'adhésion.

21 Ces quelques réserves n'enlèvent rien cependant aux qualités d'un ouvrage qui ne tardera pas, j'en suis persuadé, à devenir un classique de l'histoire agraire de la Russie et de l'histoire, tout court.

\section{NOTES}

1. De nombreuses études de N. K. Nikol'skij avaient précédé son ouvrage fondamental, KirilloBelozerskij monastyr' i ego ustrojstvo do vtoroj četverti XVII veka (1397-1625), Saint-Pétersbourg, 1910, 2 vol.

2. Cet équivalent avait déjà été proposé par J.-L. Van Regemorter ; voir la description du manse par Marc Bloch, Les caractères originaux de l'histoire rurale française, Paris, 1988, p. 190-191. La traduction des termes techniques soulève, on s'en doute, des difficultés considérables, entre autres parce que ni les documents russes, ni les documents français, en évolution constante, ne correspondent jamais rigoureusement aux définitions. Voir notamment: R. Fossier, Polyptyques et censiers, Turnhout, 1978 ( Typologie des sources du Moyen Âge occidental», $\mathrm{n}^{\circ} 28$ ) ;

G. Brunel, O. Guyotjeannin, J.-M. Moriceau, eds, Terriers et plans-terriers du XIII ${ }^{e}$ au XVIII siècle, Paris, 2002.

3. Voir A. L. Šapiro, Z. V. Dmitrieva, "Vyt" - edinica obloženija v Russkom gosudarstve XVXVIIvv. ", Srednevekovaja Rus' [mélanges R. G. Skrynnikov], Saint-Pétersbourg, 1995, p. 94-135.

4. Dans la mesure où l'on peut définir des réalités aussi mouvantes, le censier, comme son nom l'indique, récapitule les cens (redevances) dus par chaque tenancier du domaine, ainsi que les éléments d'assiette qui justifient ce montant. Le cueilloir est une simple liste de contrôle utilisée pour la perception du cens.

5. Publication : Z. V. Dmitrieva, M. N. Šaromazov, eds, Opis' stroenij i imuščestva Kirillo-Belozerskogo monastyrja 1601 goda, Saint-Pétersbourg, Peterburgskoe vostokovedenie, 1998. D'autres inventaires du même type seront effectués à Saint-Cyrille en 1615, 1621, 1635. On trouvera dans Vytnye $i$ opisnye knigi, p. 55-83, une étude des inventaires de monastères au $\mathrm{XVI}^{\mathrm{e}}$ siècle en général et, p. 4, note 7, la liste de ceux qui ont été publiés récemment (il faut y ajouter : Z. V. Dmitrieva, E. V. Krušel'nickaja, M. I. Mil'čik, eds., Opisi Soloveckogo monastyrja XVI veka, Saint-Pétersbourg, «Dmitrij Bulanin », 2003).

6. Publication : voir note 6, p. 55 de l'ouvrage.

7. Autre traduction proposée par J.-L. Van Regemorter ; le bobyl' est un paysan qui ne dispose pas d'un train de culture permettant l'exploitation d'une tenure. 
8. "...plus de 18000 četvert' de seigle, avoine, orge et froment» (p. 23). La četver' est à l'origine une mesure de capacité appliquée aux grains. Comme le "setier» français, c'est une unité de compte dont le volume n'est jamais précisé, et dont seul le poids (variable) est indiqué dans les sources. Lorsqu'elle calcule la ration annuelle (p. 146), Z. V. Dmitrieva estime la četvert' à environ 55 kilos (9 četvert' $=$ "plus de 30 puds »). Le setier a donné la "séterée », surface arable ensemencée avec un setier de grains; il existe, de même, une četvert', unité de surface, qui correspond à une četvert' de semence. Celle des arpenteurs officiels du XVII ${ }^{\mathrm{e}}$ siècle est égale à 0,5598 hectare.

9. P. 31-38; procès-verbal d'élection d'un grenetier juré, forgeron de son état, par l'assemblée cantonale, p. 32, note 102 .

10. P. 34, note 115 .

11. Pour résoudre des conflits entre le monastère et ses paysans. Le chapitre III du livre est entièrement consacré à Matfej Nikiforov et à son œuvre. Né à l'extrême fin du XvI siècle, fils d'un paysan du monastère, il devient sluga (serviteur privilégié) de Saint-Cyrille, prend les ordres le 20 octobre 1654 et exerce jusqu'en 1667 les fonctions de cellérier. Il meurt le 30 mars 1675. Bibliophile, administrateur compétent et efficace, c'est une personnalité hors du commun (p. 140-193).

12. Plus de 11 hectares (p. 204-206, tableaux 7 et 8). La desjatina équivaut à une superficie de deux četvert'. Pour Saint-Cyrille, l'auteur adopte une valeur de 1,0925 hectare.

13. Voir Agrarnaja istorija Severo-Zapada Rossii, ouvrage collectif monumental en quatre volumes paru à Leningrad (Vtoraja polovina XV-načalo XVI v., 1971 ; XVI veka, Novgorodskie pjatiny, 1974 ; XVI veka, Sever, Pskov, 1978 ; XVII veka (naselenie, zemlevladenie, zemlepol'zovanie), 1989).

14. Traduction française : Le mouvement des prix dans l'État russe du XVI ${ }^{e}$ siècle, Paris, 1957.

15. Krest'jane Russkogo Severa v XVII veke, Leningrad, 1984, p. 210-211. 